\title{
Platelet parameters in Chinese older adults with metabolic syndrome
}

\author{
Xue-Jiao Yang ${ }^{1, *}$, Le-Yang Zhang ${ }^{2, *}$, Qing-Hua $\mathrm{Ma}^{3}$, Hong-Peng Sun ${ }^{1}$, Yong $\mathrm{Xu}^{1}$, Xing Chen ${ }^{4}$ and Chen-Wei Pan \\ ${ }^{1}$ School of Public Health, Medical College of Soochow University, Suzhou, China \\ 2Medical College of Soochow University, Suzhou, China \\ ${ }^{3}$ The 3rd People's Hospital of Xiangcheng District, Suzhou, China \\ ${ }^{4}$ Department of Children Health Care, Affiliated Suzhou Hospital of Nanjing Medical University, Suzhou, China \\ Correspondence should be addressed to X Chen or C-W Pan: cx1708@126.com or pcwonly@gmail.com \\ *(X-J Yang and L-Y Zhang contributed equally to this work)
}

\begin{abstract}
Purpose: We aimed to examine the associations of platelet parameters with the presence of metabolic syndrome in community-dwelling older Chinese adults.

Methods: Study sample was from the Weitang Geriatric Diseases Study, which included 4338 individuals aged 60 years or above. The mean age of the participants was 68 years. Metabolic syndrome was defined based on the Adult Treatment Panel III criteria. Platelet parameters were assessed using an automated hematology analyzer. Multiple logistic regression models were fitted to examine relationships between the platelet parameters and the presence of metabolic syndrome after adjusting for potential confounders. Results: The adjusted odds ratio $(95 \% \mathrm{Cl})$ of metabolic syndrome for the highest quartile of platelet parameters (platelet count, mean platelet volume, plateletcrit, platelet distribution width, platelet larger cell ratio) when compared to the lowest quartile were $1.32(1.06,1.64), 1.00(0.81,1.24), 1.37(1.10,1.71), 1.45(1.14,1.83), 1.11(0.89,1.39)$, respectively. Hypertension and diabetes modified the relationship between platelet distribution width and metabolic syndrome with the associations being significant in hypertensive and non-diabetic groups. The levels of platelet distribution width increased with the risk of metabolic syndrome in men but not in women.

Conclusion: The levels of platelet count, plateletcrit and platelet distribution width increased in older adults with metabolic syndrome, suggesting that these parameters may be useful biomarkers for further risk appraisal of metabolic syndrome in aged population.
\end{abstract}

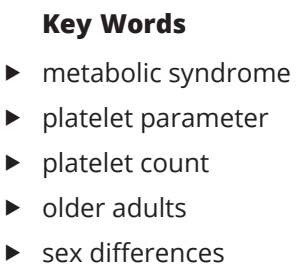

Endocrine Connections (2020) 9, 696-704

\section{Introduction}

Metabolic syndrome (MetS) affects about one-fourth of the global adult population. The prevalence of MetS has been increasing rapidly in the mainland of China over the past few decades (1), reaching 33.9\% (31.0\% in men and $36.8 \%$ in women) in 2010 (2). MetS refers to a cluster of metabolic risk factors that promote atherosclerotic cardiovascular disease and type 2 diabetes mellitus (3). Patients are not diagnosed with MetS until they manifest multiple symptoms related to obesity, dyslipidemia, hyperglycemia, and/or hypertension (3). However, any combinations of these conditions take heavy tolls on an individual's long-term health. Therefore, strategies are needed for prevention and early detection of this condition.

Platelet parameters may be promising biomarkers for predicting early signs of metabolic abnormalities. The pathophysiology of MetS includes inflammation, insulin resistance, oxidative stress and endothelial dysfunction and triggers platelet hyperactivity (4). Common platelet parameters that reflect platelet reactivity include platelet

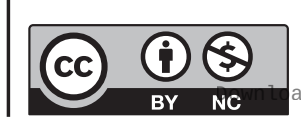

This work is licensed under a Creative Commons Attribution-NonCommercial 4.0 International License. ded from Bioscientifica.com at 04/26/2023 10:49:28AM 
count (PC), platelet distribution width (PDW), mean platelet volume (MPV), plateletcrit (PCT) and platelet larger cell ratio (P-LCR). Among them, MPV was relatively more widely investigated in epidemiological studies and was reported to be positively associated with cardiovascular events and type 2 diabetes mellitus, but its associations with MetS was inconsistent in meta-analyses $(5,6)$. Other platelet parameters are also commonly available in clinical routines and there was limited evidence supporting their roles in developing MetS. Future investigations, especially on aged population, examining the associations between a broad spectrum of platelet parameters and MetS would contribute to identifying reliable blood biomarkers for screening and early detection of MetS.

Based on a large sample of community-dwelling Chinese adults aged 60 years or older, the present study aimed to examine the association of five major platelet parameters (PC, PDW, MPV, PCT, and P-LCR) with MetS. The findings might have crucial implications in developing a cheap and easy-to-operate way for MetS screening in the communities.

\section{Methods}

\section{Study population}

The Weitang Geriatric Diseases Study is a communitybased study conducted in Weitang town located in Suzhou of China from August 2014 to January 2015. The detailed study protocol and some other findings have been reported in previous reports $(7,8,9,10,11)$. In brief, invitation letters were sent to 6030 residents aged 60 years or older in the Weitang town based on official records. Older adults were excluded if he or she had migrated from the residing address, lived in the town less than 6 months, or had died. As a result, 5613 adults were considered 'eligible' to participate. Among them, 4611 attended the clinical examination and 4579 had complete data including blood samples. In addition, 241 participants with a medical history of diseases which could potentially influence the distributions of platelet parameters (e.g. liver, blood, inflammation, tumor) were excluded from the current analyses. Ultimately, 4338 healthy participants were included.

The Weitang Geriatrics Study complied with the Helsinki Declaration and was approved by the Institutional Review Board of the Soochow University. All participants involved in this study have signed informed consent.

\section{Assessment and definition of metabolic syndrome components}

Anthropometric measurements are performed by trained medical staff following standardized procedures. Body height in centimeters and weight in kilograms were measured without shoes using a wall-mounted measuring stadiometer and a digital scale. BMI was calculated using weight in kilograms divided by height in meters squared $\left(\mathrm{kg} / \mathrm{m}^{2}\right)$. Blood pressure (BP) was measured at least three times with a minimum 5-min interval by well-trained nurses using a digital automatic blood pressure monitor. Measurements were taken under the following conditions: participants had been seated for at least $5 \mathrm{~min}$ after questionnaire completion, refrained from smoking and at least $30 \mathrm{~min}$ after blood sampling. The average of the last two readings was used in the analysis. Venous blood samples were taken after fasting for $12 \mathrm{~h}$. Blood high-density lipoprotein cholesterol (HDL-C), triglycerides, and glucose levels were measured using a chemistry analyzer (Roche cobas c 501).

According to the modified Adult Treatment Panel III (ATP III) guidelines (12), MetS was diagnosed when a participant had three or more of the following conditions: (1) BMI $\geq 25 \mathrm{~kg} / \mathrm{m}^{2}$; (2) systolic blood pressure (SBP) $\geq 130 \mathrm{mmHg}$ or diastolic blood pressure (DBP) $\geq 85 \mathrm{mmHg}$ or history of antihypertensive medication; (3) blood triglycerides $\geq 150 \mathrm{mg} / \mathrm{dL}(1.7 \mathrm{mmol} / \mathrm{L})$; (4) HDL-C of lower than $40 \mathrm{mg} / \mathrm{dL}$ (men) and $50 \mathrm{mg} / \mathrm{dL}$ (women); and (5) fasting plasma glucose $\geq 7.0 \mathrm{mmol} / \mathrm{L}$ or have been diagnosed with diabetes mellitus (13).

\section{Assessment of platelet parameters}

Five types of platelet parameters were measured in this study including platelet count (PC), mean platelet volume (MPV), platelet distribution width (PDW), plateletcrit (PCT) and large platelet ratio (P-LCR) by professional physicians in a contracted clinical laboratory. We collected the blood samples in ethylenediamine tetra acetic acid (EDTA) tube and processed them within $4 \mathrm{~h}$. The results of measurement were recorded based on public unit of measurement. For platelet parameters, normal reference ranges were as follows: PC, $150-450 \times 10^{9} / \mathrm{L} ; \mathrm{MPV}, 6.7-9.6 \mathrm{fL}$; PCT, $0.15-0.31 \%$ for women and $0.14-0.28 \%$ for men (14); PDW, $15.0-17.6 \%$ (15) and P-LCR, $21.3-51.2 \%$ for men and $21.1-51.4 \%$ for women (16).
This work is licensed under a Creative Commons Attribution-NonCommercial 4.0 International License. ded from Bioscientifica.com at 04/26/2023 10:49:28AM via free access 


\section{Assessment of covariates}

Socio-demographic data, medical history, smoking status, alcohol consumption and tea consumption were obtained through a standardized questionnaire carried out by trained interviewers. Education attainment from low to high is divided into five levels: no formal education, primary school, middle school, high school and university or above. Smoking status was classified into 'never', 'current' and 'former smoker', while alcohol and tea consumption was divided into 'drinkers' and 'non-drinkers'.

\section{Statistical analysis}

All statistical analyses were performed using commercial software IBM SPSS version 25.0 (Spss Inc). Descriptive analyses included mean and S.D. for continuous variables and frequency for categorical and ordinal variables. The differences in platelet parameters between older adults with and without MetS were compared using the Student's t-test. Participants were divided into four quartiles by the level of platelet parameters. Multiple logistic regression models were fitted to examine relationships between the quartiles of platelet parameters and the presence of MetS after adjusting for sex, age, smoking status and alcohol drinking status as covariates. Adjusted odds ratios (ORs) and corresponding 95\% CIs were used to assess the strength of the platelet-MetS relationship. We also assessed the association of MetS components with platelet parameters in multivariable models.
Since hypertension and diabetes mellitus are the major causes of MetS, we further conducted a stratified analysis of the population with these two conditions. The relationships between platelet parameters and MetS and its components in different disease status were analyzed. We also investigated the potential interaction between gender and platelet parameters, and the results of the gender stratification analysis are shown in a forest plot. In all analyses, two-sided $P$ values $<0.05$ were considered as the level of statistical significance.

\section{Results}

In this analysis, 820 out of 4338 (18.9\%) individuals were found to be affected by MetS based on the ATP III criteria. Platelet parameters of the study population by metabolic syndrome status are displayed in Table 1. Subjects with MetS had significantly higher levels of PC $(167 \pm 48.5)$, PDW $(16.1 \pm 1.06)$ and PCT $(0.16 \pm 0.04)$ compared to those without (PC: $161 \pm 50.3$, PDW: $16.0 \pm 1.14$, PCT: $0.16 \pm 0.04, P<0.05$ for all). However, levels of MPV and P-LCR were not different between the two groups. When stratified by gender, higher levels of PDW was observed $(P<0.01)$ in men with MetS. In women, levels of PC and PCT were significantly higher in subjects with MetS compared to those without.

Table 2 shows the associations between platelet parameters and MetS after adjusting for potential confounders. We found that participants with MetS tended to have higher levels of PDW, PC and PCT.

Table 1 Platelet parameters of the study population by metabolic syndrome status.

\begin{tabular}{|c|c|}
\hline Platelet parameters & $n$ \\
\hline All persons & $n=4338$ \\
\hline Platelet count, mean (s.D.), 1099/L & $162(50.1)$ \\
\hline Mean platelet volume, mean (s.D.), fL & $9.84(1.29)$ \\
\hline Platelet crit, mean (s.D.), \% & $0.16(0.04)$ \\
\hline Platelet distribution width, mean (s.D.), \% & $16.1(1.13)$ \\
\hline Large platelet ratio, mean (s.D.), \% & $35.7(10.7)$ \\
\hline Men & $n=2117$ \\
\hline Platelet count, mean (s.D.), $10^{9} / \mathrm{L}$ & $159(50.2)$ \\
\hline Mean platelet volume, mean (s.D.), fL & $9.78(1.29)$ \\
\hline Platelet crit, mean (s.D.), \% & $0.15(0.04)$ \\
\hline Platelet distribution width, mean (s.D.), \% & $16.1(1.17)$ \\
\hline Large platelet ratio, mean (s.D.), \% & $35.0(10.5)$ \\
\hline Women & $n=2221$ \\
\hline Platelet count, mean (s.D.), $10^{9} / \mathrm{L}$ & $166(49.6)$ \\
\hline Mean platelet volume, mean (s.D.), fL & $9.91(1.29)$ \\
\hline Platelet crit, mean (s.D.), \% & $0.16(0.04)$ \\
\hline Platelet distribution width, mean (s.D.), \% & $16.0(1.09)$ \\
\hline Large platelet ratio, mean (s.D.), \% & $36.4(10.8)$ \\
\hline
\end{tabular}

\begin{tabular}{c} 
Metabo \\
\hline Absent \\
\hline$n=3518$ \\
$161(50.3)$ \\
$9.84(1.29)$ \\
$0.16(0.04)$ \\
$16.0(1.14)$ \\
$35.6(10.6)$ \\
$n=1832$ \\
$159(50.6)$ \\
$9.78(1.29)$ \\
$0.15(0.04)$ \\
$16.0(1.20)$ \\
$34.9(10.5)$ \\
$n=1686$ \\
$165(49.9)$ \\
$9.92(1.29)$ \\
$0.16(0.04)$ \\
$16.0(1.08)$ \\
$36.4(10.8)$ \\
CC \\
\hline $\mathbf{S Y}(\$)$ \\
\hline
\end{tabular}


Table 2 Relationships of platelet parameters to the prevalence of metabolic syndrome.

\begin{tabular}{l}
\hline \\
\hline Platelet count, 10\%/L \\
Q1 (<129) \\
Q2 (130-160) \\
Q3 (161-191) \\
Q4 (>192) \\
Mean platelet volume, fL \\
Q1 (<8.9) \\
Q2 (9.0-9.7) \\
Q3 (9.8-10.6) \\
Q4 (>10.7) \\
Platelet crit, \% \\
Q1 (<0.130) \\
Q2 (0.131-0.154) \\
Q3 (0.155-0.180) \\
Q4 (>0.181) \\
Platelet distribution width, $\%$ \\
Q1 (<15.8) \\
Q2 (15.9-16.1) \\
Q3 (16.2-16.5) \\
Q4 (>16.5) \\
Platelet larger cell ratio, \% \\
Q1 (<27.9) \\
Q2 (28.0-34.7) \\
Q3 (34.8-42.0) \\
Q4 (>42.0)
\end{tabular}

\begin{tabular}{ccc}
\hline Unadjusted model & \\
\hline OR $(95 \% \mathrm{Cl})$ & & $P$ value \\
\cline { 1 - 1 } $1.002(1.001,1.004)$ & & $<0.01$ \\
Reference & & \\
$1.21(0.97,1.51)$ & & 0.09 \\
$1.12(0.90,1.40)$ & & 0.33 \\
$1.45(1.17,1.80)$ & & $<0.01$ \\
$1.00(0.94,1.06)$ & & 0.94 \\
Reference & & \\
$0.98(0.79,1.21)$ & & 0.84 \\
$0.91(0.73,1.13)$ & & 0.40 \\
$1.04(0.84,1.29)$ & & 0.72 \\
$1.38(1.15,1.66)$ & & $<0.01$ \\
Reference & & \\
$1.19(0.95,1.49)$ & & 0.12 \\
$1.26(1.01,1.57)$ & & $<0.05$ \\
$1.58(1.28,1.97)$ & & $<0.01$ \\
$1.09(1.02,1.17)$ & & $<0.05$ \\
Reference & & \\
$1.31(1.05,1.64)$ & $<0.05$ \\
$1.59(1.28,1.96)$ & $<0.01$ \\
$1.36(1.08,1.72)$ & $<0.01$ \\
$1.003(0.996,1.011)$ & 0.35 \\
Reference & \\
$1.08(0.87,1.34)$ & 0.51 \\
$1.16(0.94,1.44)$ & 0.17 \\
$1.17(0.94,1.45)$ & 0.16 \\
\hline
\end{tabular}

\begin{tabular}{|c|c|}
\hline \multicolumn{2}{|c|}{ Multiple adjusted model ${ }^{a}$} \\
\hline OR $(95 \% \mathrm{Cl})$ & $P$ value \\
\hline $1.001(1.000,1.003)$ & 0.05 \\
\hline \multicolumn{2}{|l|}{ Reference } \\
\hline $1.22(0.97,1.52)$ & 0.09 \\
\hline $1.05(0.84,1.32)$ & 0.66 \\
\hline $1.32(1.06,1.64)$ & $<0.05$ \\
\hline $0.99(0.93,1.05)$ & 0.61 \\
\hline \multicolumn{2}{|l|}{ Reference } \\
\hline $0.97(0.78,1.20)$ & 0.76 \\
\hline $0.87(0.70,1.09)$ & 0.22 \\
\hline $1.00(0.81,1.24)$ & 0.99 \\
\hline $1.24(1.03,1.49)$ & $<0.05$ \\
\hline \multicolumn{2}{|l|}{ Reference } \\
\hline $1.14(0.91,1.43)$ & 0.26 \\
\hline $1.15(0.92,1.44)$ & 0.22 \\
\hline $1.37(1.10,1.71)$ & $<0.01$ \\
\hline $1.11(1.03,1.19)$ & $<0.01$ \\
\hline \multicolumn{2}{|l|}{ Reference } \\
\hline $1.32(1.06,1.66)$ & $<0.05$ \\
\hline $1.65(1.33,2.05)$ & $<0.01$ \\
\hline $1.45(1.14,1.83)$ & $<0.01$ \\
\hline $1.00(0.99,1.01)$ & 0.70 \\
\hline \multicolumn{2}{|l|}{ Reference } \\
\hline $1.07(0.86,1.34)$ & 0.54 \\
\hline $1.12(0.90,1.40)$ & 0.30 \\
\hline $1.11(0.89,1.39)$ & 0.34 \\
\hline
\end{tabular}

${ }^{a}$ Adjusted for gender, age, smoking status (never, current and former smoker), and alcohol drinking status (drinkers and non-drinkers).

For example, the OR of MetS for the highest vs lowest quartile of PDW, PC and PCT were 1.45 (95\% CI:1.14-1.83), 1.32 (95\% CI:1.06-1.64) and 1.37 (95\% CI:1.10-1.71) in multiple-adjusted models, respectively (all $P<0.05$ ). No significant associations were observed between levels of MPV/P-LCR and the presence of MetS.

We also assessed the association of MetS components with platelet parameters (Table 3). Results indicated that the increased PC and PCT level was significantly correlated with three MetS factors $(P<0.05$ for all) and that the level of PDW was correlated with the high blood triglycerides (OR:1.13, 95\% CI: $(1.05,1.21)$ ).

We further examined the relationship between platelet parameters and MetS in subgroup analyses stratified by the presence of diabetes or hypertension and gender (Tables 4 and 5). We found that the presence of hypertension or diabetes modified the relationship between PDW and MetS. Among individuals with hypertension, levels of PDW showed a positive association with MetS $(P<0.01)$, while this associations were not observed in

Table 3 Odds ratios (ORs) and 95\% Cls for the association between platelet parameters and each criterion of metabolic syndrome.

\begin{tabular}{|c|c|}
\hline & Overweight/obesity \\
\hline & $\mathrm{OR}^{\mathrm{a}}(95 \% \mathrm{Cl})$ \\
\hline Platelet count, $10^{9} / \mathrm{L}$ & $\begin{array}{c}1.001(1.000,1.003) \\
P=0.13\end{array}$ \\
\hline $\begin{array}{l}\text { Mean platelet } \\
\text { volume, } \mathrm{fL}\end{array}$ & $\begin{array}{c}1.01(0.96,1.08) \\
P=0.66\end{array}$ \\
\hline Platelet crit, \% & $\begin{array}{c}1.25(1.03,1.50) \\
P<0.05\end{array}$ \\
\hline $\begin{array}{l}\text { Platelet distribution } \\
\text { width, \% }\end{array}$ & $\begin{array}{c}1.03(0.96,1.10) \\
P=0.48\end{array}$ \\
\hline $\begin{array}{l}\text { Platelet larger cell } \\
\text { ratio, \% }\end{array}$ & $\begin{array}{c}1.004(0.996,1.011) \\
P=0.32\end{array}$ \\
\hline
\end{tabular}

\begin{tabular}{c}
\hline Elevated BP \\
\hline $\mathrm{OR}^{\mathrm{a}}(95 \% \mathrm{Cl})$ \\
\hline $1.004(1.002,1.005)$ \\
$P<0.01$ \\
$1.00(0.94,1.07)$ \\
$P=0.96$ \\
$1.75(1.39,2.20)$ \\
$P<0.01$ \\
$1.01(0.94,1.09)$ \\
$P=0.77$ \\
$1.00(0.99,1.01)$ \\
$P=0.96$
\end{tabular}

\begin{tabular}{c}
\hline Elevated TG \\
\hline $\mathrm{OR}^{\mathrm{a}}(95 \% \mathrm{Cl})$ \\
\hline $1.002(1.001,1.004)$ \\
$P<0.01$ \\
$0.97(0.92,1.03)$ \\
$P=0.36$ \\
$1.32(1.11,1.58)$ \\
$P<0.01$ \\
$1.13(1.05,1.21)$ \\
$P<0.01$ \\
$1.00(0.99,1.01)$ \\
$P=0.36$
\end{tabular}

\begin{tabular}{|c|}
\hline Reduced HDL-C \\
\hline $\mathrm{OR}^{\mathrm{a}}(95 \% \mathrm{Cl})$ \\
\hline $1.002(1.000,1.003)$ \\
\hline$P<0.05$ \\
\hline $0.92(0.87,0.98)$ \\
\hline$P<0.01$ \\
\hline $1.12(0.94,1.34)$ \\
\hline$P=0.22$ \\
\hline $1.05(0.98,1.12)$ \\
\hline$P=0.20$ \\
\hline $0.992(0.985,0.999)$ \\
\hline$P<0.05$ \\
\hline
\end{tabular}

\begin{tabular}{c}
\hline Elevated FPG \\
\hline $\mathrm{OR}^{\mathrm{a}}(95 \% \mathrm{Cl})$ \\
\hline $0.999(0.997,1.001)$ \\
$P=0.52$ \\
$1.04(0.96,1.12)$ \\
$P=0.32$ \\
$0.84(0.61,1.16)$ \\
$P=0.28$ \\
$1.05(0.95,1.15)$ \\
$P=0.34$ \\
$1.01(1.00,1.02)$ \\
$P=0.12$
\end{tabular}

adjusted for gender, age, smoking status (never, current and former smoker), and alcohol drinking status (drinkers and non-drinkers). BP, blood pressure; FPG, fasting plasma glucose; HDL-C, high-density lipoprotein cholesterol; TG, triglycerides. 


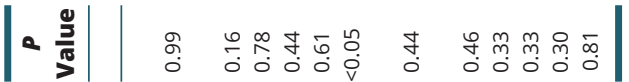

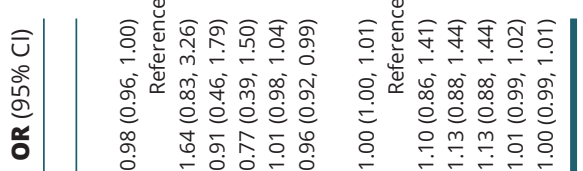

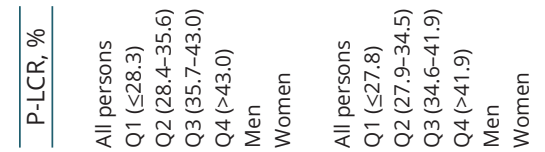

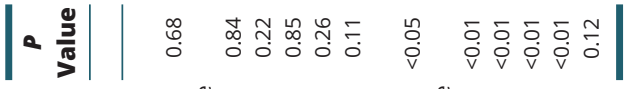
บ||

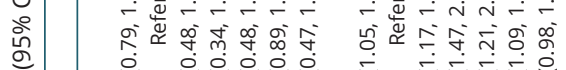

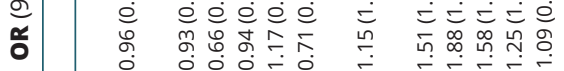

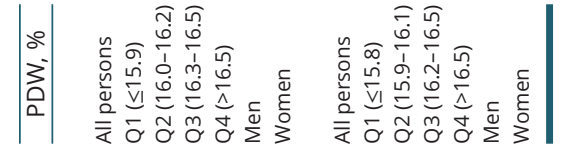

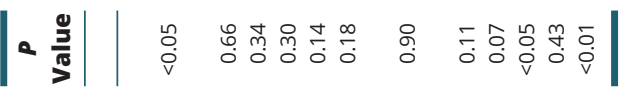

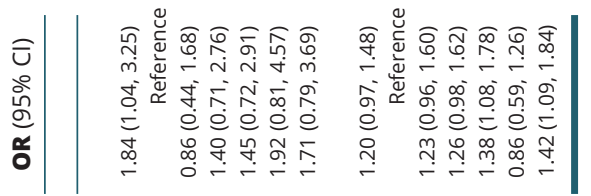

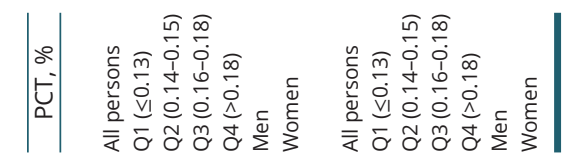

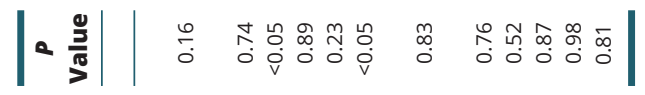

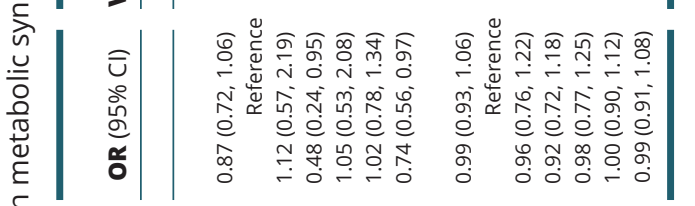

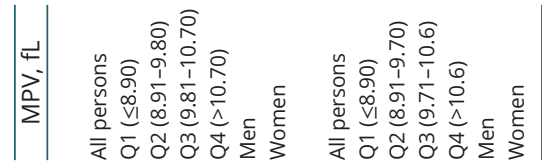

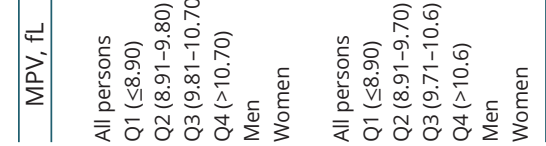

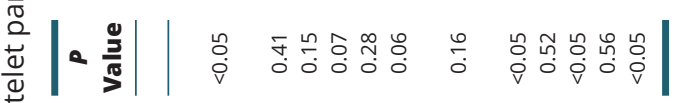

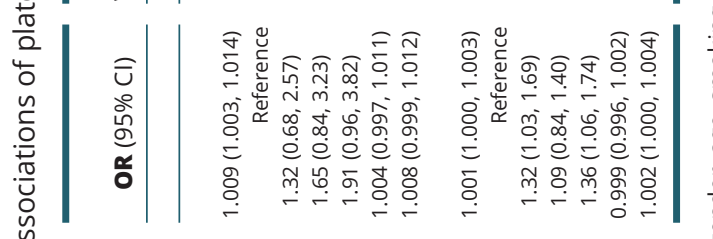

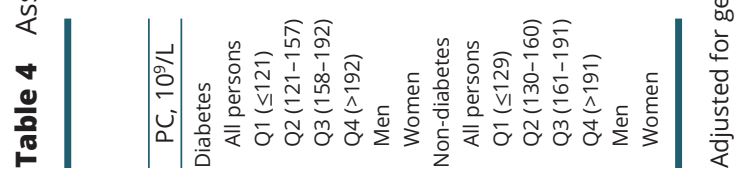

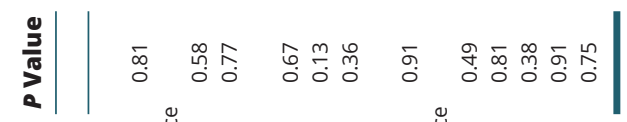

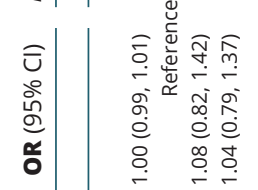

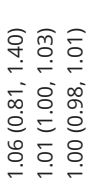

ชั

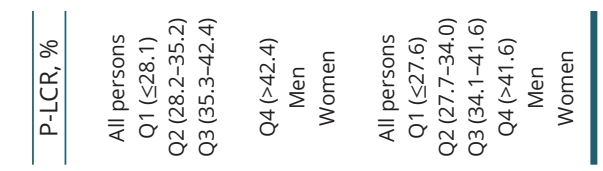

$\left|+\frac{2}{3}\right|$

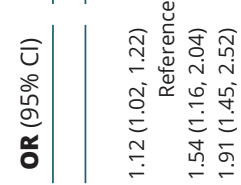

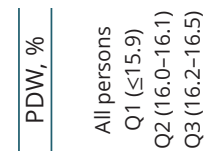

$a \frac{\stackrel{9}{\frac{\pi}{5}}}{>} \mid$

远

ते

등

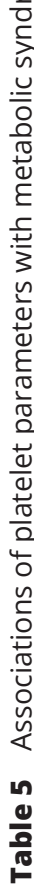

ษิ

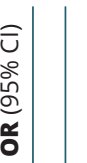

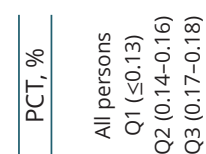

敦|

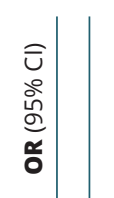

m $\cong$

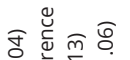

ठัष

仓

$\begin{array}{lll}\hat{n} & \infty & \bar{\infty} \\ 0 & 0 & 0 \\ 0 & 0 & 0\end{array}$

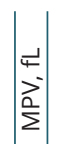

등ํㅇำ

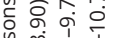

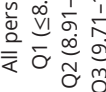

$\mid$

ז.

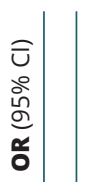

ชิ

o

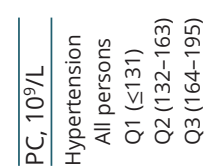

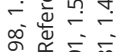

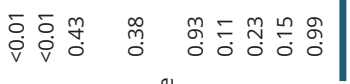

$8=\hat{A}$

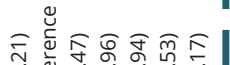

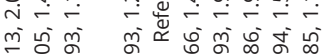

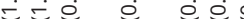

ํํำ

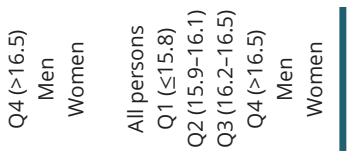

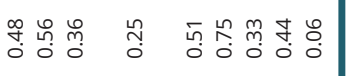

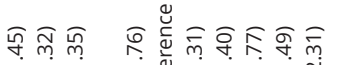

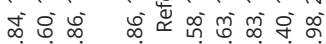

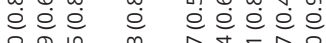

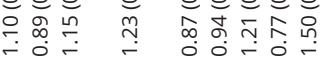

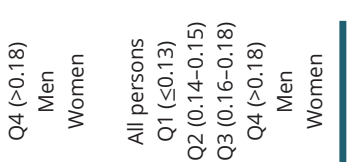

年会云

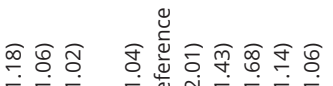

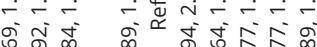

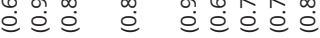

ด̆

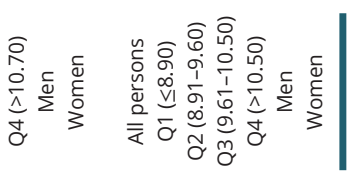

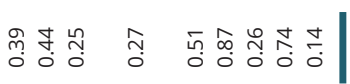

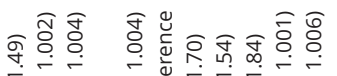

एँ

थें

m

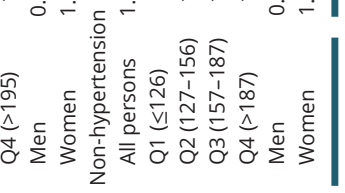




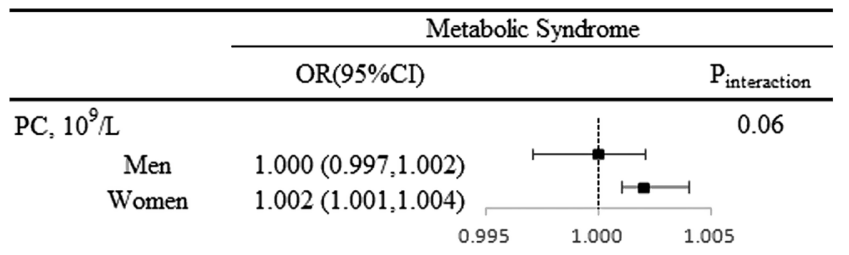

MPV, fL

$$
\text { Men }
$$

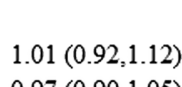

Women

$0.97(0.90,1.05)$

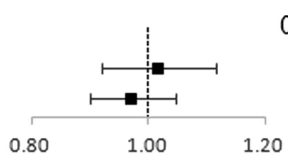

PCT, \%

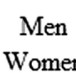

$1.01(0.73,1.40)$ $1.39(1.10,1.76)$

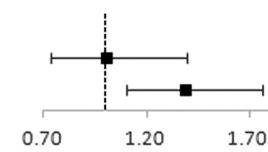

PDW, \% Men
Wome $1.23(1.08,1.39)$
$1.04(0.95,1.14)$

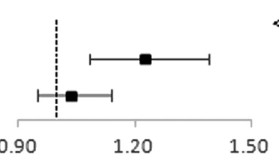

P-LCR, \% Men Women

$1.008(0.996,1.120)$

$0.998(0.989 .1 .007)$

0.45

0.60

$<0.01$ 0.15

\section{Figure 1}

Subgroup analyses of the association between platelet parameters and MetS. Interactions between platelet parameters and sex on the MetS were tested by the likelihood ratio test with adjustment for the same variables as multiple model in Table 2 in addition to sex. Odds ratio and $95 \% \mathrm{Cls}$ were showed by forest plot.

non-hypertensive ones. In the stratified analysis of diabetes, however, this relationship was only significant in men without diabetes. Meanwhile, the relationships between PC/PCT and MetS were always significant in diabetic participants. In addition, significant interaction effect of gender on the relationship between levels of PDW and MetS were observed ( $P$ value for interaction $<0.01$ ).
In subsequent analyses stratified by gender (Fig. 1), the levels of PDW increased with the risk of MetS in men but not in women.

Table 6 shows that high BP and high triglycerides were accompanied by increased levels of PC and PCT in nondiabetes participants. Meanwhile, as shown in Table 7, PC and PCT levels were associated with high triglycerides in patients with hypertension.

\section{Discussion}

In the present study, we found that some platelet parameters such as PC, PCT and PDW were significantly associated with MetS in a large sample of communitydwelling older adults. In general, older individuals with MetS tended to have higher PC, PCT and PDW levels compared with those without. Moreover, gender and the presence of hypertension and diabetes modified the association between PDW and MetS. These findings added new knowledge on role of platelets in the pathogenesis of MetS and may help to develop early diagnostic strategies for MetS-related complications.

To the best of our knowledge, this is the first study assessing the relationship of platelet parameters with MetS in older adults. PDW represents the morphologic changes and the activity of platelets (17). Therefore, elevated PDW indicates the presence of larger, younger and more active platelets in peripheral blood $(6,18,19)$. The biological mechanisms underlying observed associations between MetS and PDW are not fully elucidated, but some possibilities have been suggested. Insulin resistance plays an important role in the development of MetS and type 2 diabetes mellitus. Vascular dysfunction caused by insulin resistance may lead to a decrease in prostacyclin and nitric

Table 6 Associations of platelet parameters with components of metabolic syndrome by diabetes.

\begin{tabular}{|c|c|c|}
\hline & \multicolumn{2}{|l|}{ Elevated BP } \\
\hline & OR $(95 \% \mathrm{Cl})$ & $P$ value \\
\hline \multicolumn{3}{|l|}{ Diabetes } \\
\hline $\mathrm{PC}, 10^{9} / \mathrm{L}$ & $1.00(0.99,1.01)$ & 0.56 \\
\hline MPV, fL & $1.07(0.74,1.54)$ & 0.73 \\
\hline PCT, \% & $1.97(0.65,6.00)$ & 0.23 \\
\hline PDW, \% & $1.27(0.67,1.97)$ & 0.08 \\
\hline P-LCR, \% & $1.01(0.97,1.06)$ & 0.58 \\
\hline \multicolumn{3}{|l|}{ Non-diabetes } \\
\hline $\mathrm{PC}, 10^{9} / \mathrm{L}$ & $1.004(1.002,1.006)$ & $<0.05$ \\
\hline MPV, fL & $1.00(0.93,1.07)$ & 0.94 \\
\hline PCT, \% & $1.77(1.40,2.24)$ & $<0.05$ \\
\hline PDW, \% & $1.00(0.93,1.08)$ & 0.92 \\
\hline P-LCR, \% & $1.00(1.00,1.01)$ & 0.82 \\
\hline
\end{tabular}

\begin{tabular}{|c|c|}
\hline \multicolumn{2}{|c|}{ Elevated BMI } \\
\hline OR $(95 \% \mathrm{CI})$ & $P$ value \\
\hline $1.00(1.00,1.01)$ & 0.45 \\
\hline $1.00(0.82,1.22)$ & 0.99 \\
\hline $1.36(0.76,2.43)$ & 0.31 \\
\hline $1.19(0.66,2.16)$ & 0.56 \\
\hline $1.00(0.89,1.03)$ & 0.88 \\
\hline $1.000(0.999,1.003)$ & 0.23 \\
\hline $1.02(0.96,1.08)$ & 0.59 \\
\hline $1.22(1.00,1.49)$ & 0.05 \\
\hline $1.02(0.95,1.10)$ & 0.61 \\
\hline $1.00(1.00,1.01)$ & 0.29 \\
\hline
\end{tabular}

\begin{tabular}{ccc}
\hline \multicolumn{2}{c}{ Elevated TG } \\
\cline { 1 - 1 } \cline { 1 - 1 } OR $(95 \% \mathrm{Cl})$ & & $P$ value \\
\cline { 1 - 1 } $1.01(1.00,1.01)$ & & $<0.05$ \\
$0.84(0.69,1.03)$ & & 0.10 \\
$1.63(0.93,2.87)$ & & 0.09 \\
$1.09(0.88,1.35)$ & & 0.55 \\
$0.98(0.96,1.01)$ & & 0.19 \\
& & \\
$1.002(1.000,1.003)$ & $<0.05$ \\
$0.99(0.93,1.05)$ & & 0.61 \\
$1.29(1.07,1.55)$ & $<0.01$ \\
$1.13(1.05,1.22)$ & $<0.01$ \\
$1.01(1.00,1.01)$ & 0.19 \\
\hline
\end{tabular}

\begin{tabular}{crr}
\hline \multicolumn{2}{c}{ Reduced HDL-C } \\
\hline \multicolumn{1}{c}{ OR $(95 \% \mathrm{Cl})$} & & $P$ value \\
\cline { 1 - 2 } $1.00(1.00,1.01)$ & & 0.74 \\
$0.93(0.76,1.14)$ & & 0.49 \\
$1.04(0.59,1.83)$ & & 0.90 \\
$0.90(0.73,1.11)$ & & 0.32 \\
$0.99(0.96,1.01)$ & & 0.29 \\
& & \\
$1.002(1.000,1.003)$ & $<0.05$ \\
$0.92(0.86,0.98)$ & & $<0.01$ \\
$1.13(0.93,1.21)$ & & 0.21 \\
$1.07(0.99,1.15)$ & & 0.09 \\
$0.99(0.99,1.10)$ & $<0.05$ \\
\hline
\end{tabular}

Adjusted for gender, age, smoking status (never, current and former smoker), and alcohol drinking status (drinkers and non-drinkers). BP blood pressure, TG triglycerides, HDL-C high-density lipoprotein cholesterol.

https://ec.bioscientifica.com https://doi.org/10.1530/EC-20-0209 (c) 2020 The authors Published by Bioscientifica Ltd

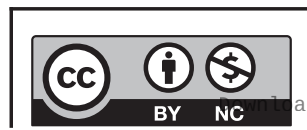

This work is licensed under a Creative Commons Attribution-NonCommercial 4.0 International License. ded from Bioscientifica.com at 04/26/2023 10:49:28AM via free access 
Table 7 Associations of platelet parameters with components of metabolic syndrome by hypertension.

\begin{tabular}{|c|c|c|}
\hline & \multicolumn{2}{|c|}{ Elevated FPG } \\
\hline & OR $(95 \% \mathrm{Cl})$ & $P$ value \\
\hline \multicolumn{3}{|c|}{ Hypertension } \\
\hline $\mathrm{PC}, 10^{9} / \mathrm{L}$ & $0.998(0.996,1.001)$ & 0.21 \\
\hline MPV, fL & $1.03(0.94,1.12)$ & 0.60 \\
\hline PCT, \% & $1.14(0.10,2.73)$ & 0.20 \\
\hline PDW, \% & $1.06(0.95,1.19)$ & 0.27 \\
\hline P-LCR, \% & $1.01(1.00,1.02)$ & 0.70 \\
\hline \multicolumn{3}{|c|}{ Non-hypertension } \\
\hline $\mathrm{PC}, 10^{9} / \mathrm{L}$ & $0.999(0.995,1.003)$ & 0.70 \\
\hline MPV, fL & $1.04(0.90,1.27)$ & 0.60 \\
\hline PCT, \% & $0.96(0.58,1.60)$ & 0.87 \\
\hline PDW, \% & $0.98(0.83,1.15)$ & 0.80 \\
\hline P-LCR, \% & $1.01(0.99,1.03)$ & 0.44 \\
\hline
\end{tabular}

\begin{tabular}{|c|c|}
\hline \multicolumn{2}{|l|}{ Elevated BMI } \\
\hline OR $(95 \% \mathrm{CI})$ & $P$ value \\
\hline $1.000(0.998,1.002)$ & 0.95 \\
\hline $1.03(0.95,1.11)$ & 0.47 \\
\hline $0.96(0.18,21.01)$ & 0.58 \\
\hline $1.03(0.94,1.12)$ & 0.55 \\
\hline $1.01(1.00,1.02)$ & 0.20 \\
\hline $1.002(0.998,1.004)$ & 0.18 \\
\hline $0.97(0.88,1.08)$ & 0.61 \\
\hline $1.28(0.92,1.78)$ & 0.15 \\
\hline $1.00(0.89,1.12)$ & 0.99 \\
\hline $1.00(0.99,1.01)$ & 0.96 \\
\hline
\end{tabular}

\begin{tabular}{c}
\hline Elevated TG \\
\hline OR $(95 \% \mathrm{Cl})$ \\
\hline $1.002(1.000,1.004)$ \\
$0.93(0.87,1.01)$ \\
$1.25(1.01,1.56)$ \\
$1.09(1.00,1.19)$ \\
$1.00(0.99,1.01)$ \\
$1.000(0.998,1.003)$ \\
$1.02(0.93,1.13)$ \\
$1.16(0.85,1.59)$ \\
$1.19(1.05,1.36)$ \\
$1.01(1.00,1.02)$ \\
\hline
\end{tabular}

\begin{tabular}{r}
$P$ value \\
\hline \\
$<0.05$ \\
0.07 \\
$<0.05$ \\
0.05 \\
0.08 \\
\\
0.54 \\
0.63 \\
0.35 \\
$<0.01$ \\
0.14
\end{tabular}

\begin{tabular}{ccc}
\hline \multicolumn{2}{c}{ Reduced HDL-C } \\
\hline OR $(95 \% \mathrm{Cl})$ & & $P$ value \\
\cline { 1 - 1 } & & \\
$1.002(1.000,1.004)$ & & $<0.05$ \\
$0.90(0.83,0.97)$ & & $<0.01$ \\
$1.11(0.89,1.40)$ & & 0.35 \\
$1.03(0.94,1.12)$ & & 0.55 \\
$0.99(0.98,1.00)$ & & $<0.05$ \\
& & \\
$1.001(0.998,1.003)$ & & 0.66 \\
$1.95(0.87,1.04)$ & & 0.25 \\
$0.96(0.71,1.30)$ & & 0.79 \\
$1.07(0.96,1.19)$ & 0.25 \\
$1.00(0.98,1.01)$ & 0.37 \\
\hline
\end{tabular}

Adjusted for gender, age, smoking status (never, current and former smoker), and alcohol drinking status (drinkers and non-drinkers). FPG, fasting plasma glucose; HDL-C, high-density lipoprotein cholesterol; TG, triglycerides.

oxide production by the vascular endothelium, resulting in promoting increased platelet activity (20). Furthermore, a plethora of studies have indicated that platelet activation is associated with the development of atherosclerosis and thrombosis, which is a result of MetS components such as hypertension, obesity, and inflammation. People with atherosclerosis and thrombosis exhibit greater platelet activation, which promotes increased peripheral platelet consumption, resulting in platelets produced by the bone marrow being larger and more active.

We also found that levels of PC/PCT were higher in older adults with MetS than those without. In accordance with results of Table 3, both PC and PCT were associated with three components of MetS. First, it is suggested that metabolic disorders are often accompanied by lowgrade inflammation (21), characterized by increased secretion of a variety of adipokines and cytokines such as adiponectin, interleukin 6 (IL-6), and tumor necrosis factor- $\alpha$ (TNF- $\alpha$ ), leading to changes in levels of PC (22). Meanwhile, the value of PCT is derived from PC and MPV with increased PC levels being associated with higher PCT levels. Secondly, physical activity showed a significant and inverse dose-response relationship with levels of PC (23). PC can also be influenced by nutritional status, which is closely related to metabolic function. Martin et al. (24) demonstrated that the animals on the highcholesterol diet had significantly higher levels of PC than the control group, which indicates that a high-cholesterol diet produces might change platelet production. The development of MetS is highly dependent of physical activity, nutrition, lifestyle, and family genetics and these risk factors for MetS may, at least partially, explain the relationship between PC/PCT and MetS. This also explains the increased levels of PC and PCT in people who have both high BP and high triglycerides. Our study suggested that the presence of hypertension modified the association between increased PDW levels in people who had both hypertension and MetS. High blood pressure might cause endothelial dysfunction and vascular damage, which promotes platelet activation and adhesion (25). According to previous studies, PDW is a more specific marker of platelet activation than MPV (26). Furthermore, hypertension is a major risk factor for cardiovascular disease (CVD) (27) and PDW associated with or predicting cardiovascular disorders (28).

Our study showed that the association of PC/PCT with MetS was gender specific and was significant in women rather than men. This finding was consistent with some previous studies $(29,30)$. We provided some explanations for the gender difference in the PC/PCT-MetS associations. First, women tend to have higher body fat rates than men with similar BMI. Pro-inflammatory cytokines are released by perivascular white adipose tissue, which may increase the numbers of platelets and lead to chronic lowgrade inflammation (31). Second, there are differences in lifestyles between men and women. Chinese men are significantly more likely to smoke and drink alcohol than women. Cigarette smoking has been shown to increase platelet count and platelet aggregation $(32,33)$, while alcohol consumption can lead to abnormalities in platelet function $(34,35)$. Third, higher testosterone levels might be associated with a reduced risk of MetS in men and an elevated risk in women (36). Thus, one may hypothesize that gender-specific sex hormones may explain some of this phenomenon. Our study had a relatively large sample size so that the study power was sufficient to detect the association between platelet parameters and MetS as well as some possible interaction effects. However, some 
limitations exist in the current study. First, the causal relationship could not be identified because of the nature of the cross-sectional design. It is also likely that MetS may result in a higher level of platelet parameters. In addition, although some confounding factors have been adjusted, other potential confounding effects (such as long-term medication) may still exist and may distort the findings.

In conclusion, our study provided preliminary evidence on the association between platelet parameters including PC, PCT and PDW and MetS in older Chinese adults. Higher PC/PCT levels tended to increase the risk of MetS in women and increased PDW levels in hypertensive patients was associated with MetS. Longitudinal cohort studies are warranted to confirm the findings and evaluate the power and ability of platelet parameters in predicting MetS and its associated complications.

\section{Declaration of interest}

The authors declare that there is no conflict of interest that could be perceived as prejudicing the impartiality of the research reported.

\section{Funding}

This study was supported by the Science and Technology Bureau of Xiangcheng District in Suzhou, China, under grant no. XJ201706 and the Health Commission of Suzhou under grant no. GSWS2019090.

\section{Ethical approval}

This study was conducted complying with the tenets of the Helsinki Declaration and with the approval of the Institutional Review Board of Soochow University.

\section{References}

1 Gu D, Reynolds K, Wu X, Chen J, Duan X, Reynolds RF, Whelton PK $\&$ He J. Prevalence of the metabolic syndrome and overweight among adults in China. Lancet 2005365 1398-1405. (https://doi. org/10.1016/S0140-6736(05)66375-1)

2 Lu J, Wang L, Li M, Xu Y, Jiang Y, Wang W, Li J, Mi S, Zhang M, Li Y, et al. Metabolic syndrome among adults in China: the 2010 China noncommunicable disease surveillance. Journal of Clinical Endocrinology and Metabolism 2017102 507-515. (https://doi. org/10.1210/jc.2016-2477)

3 Alberti KG, Zimmet P, Shaw J \& IDF Epidemiology Task Force Consensus Group. The metabolic syndrome - a new worldwide definition. Lancet 2005366 1059-1062. (https://doi.org/10.1016/ S0140-6736(05)67402-8)

4 Santilli F, Vazzana N, Liani R, Guagnano MT \& Davi G. Platelet activation in obesity and metabolic syndrome. Obesity Reviews 2012 13 27-42. (https://doi.org/10.1111/j.1467-789X.2011.00930.x)

5 Chu SG, Becker RC, Berger PB, Bhatt DL, Eikelboom JW, Konkle B, Mohler ER, Reilly MP \& Berger JS. Mean platelet volume as a predictor of cardiovascular risk: a systematic review and metaanalysis. Journal of Thrombosis and Haemostasis 20108 148-156. (https://doi.org/10.1111/j.1538-7836.2009.03584.x)
6 Zaccardi F, Rocca B, Pitocco D, Tanese L, Rizzi A \& Ghirlanda G. Platelet mean volume, distribution width, and count in type 2 diabetes, impaired fasting glucose, and metabolic syndrome: a metaanalysis. Diabetes/Metabolism Research and Reviews 201531 402-410. (https://doi.org/10.1002/dmrr.2625)

7 Yang XJ, Tian S, Ma QH, Sun HP, Xu Y \& Pan CW. Leukocyte-related parameters in older adults with metabolic syndrome. Endocrine 2020 68 312-319. (https://doi.org/10.1007/s12020-020-02243-2)

8 Qian YX, Liu JH, Ma QH, Sun HP, Xu Y \& Pan CW. Associations of sleep durations and sleep-related parameters with metabolic syndrome among older Chinese adults. Endocrine 201966 240-248. (https://doi.org/10.1007/s12020-019-02064-y)

9 Liu JH, Ma QH, Sun HP, Xu Y \& Pan CW. Depressive symptom as a mediator of the influence of self-reported sleep quality on falls: a mediation analysis. Aging and Mental Health 2020 1-6. (https://doi. org/10.1080/13607863.2020.1711860)

10 Liu JH, Qian YX, Ma QH, Sun HP, Xu Y \& Pan CW. Depressive symptoms and metabolic syndrome components among older Chinese adults. Diabetology and Metabolic Syndrome 20201218. (https://doi.org/10.1186/s13098-020-00526-2)

11 Liu JH, Zhang YJ, Ma QH, Sun HP, Xu Y \& Pan CW. Elevated blood neutrophil to lymphocyte ratio in older adults with cognitive impairment. Archives of Gerontology and Geriatrics $20208 \mathbf{8 8} 104041$. (https://doi.org/10.1016/j.archger.2020.104041)

12 Expert Panel on Detection, Evaluation, and Treatment of High Blood Cholesterol in Adults. Executive summary of the third report of the National Cholesterol Education Program (NCEP) Expert Panel on Detection, evaluation, and treatment of high blood cholesterol in adults (Adult Treatment Panel III). JAMA 2001285 2486-2497. (https://doi.org/10.1001/jama.285.19.2486)

13 Sabanayagam C, Wang JJ, Mitchell P, Tan AG, Tai ES, Aung T, Saw SM $\&$ Wong TY. Metabolic syndrome components and age-related cataract: the Singapore Malay eye study. Investigative Ophthalmology and Visual Science 201152 2397-2404. (https://doi.org/10.1167/ iovs.10-6373)

14 Kim MJ, Park PW, Seo YH, Kim KH, Seo JY, Jeong JH, Park MJ, Jung JW \& Ahn JY. Reference intervals for platelet parameters in Korean adults using Advia 2120. Annals of Laboratory Medicine 2013 33 364-366. (https://doi.org/10.3343/alm.2013.33.5.364)

15 Hoffmann JJ, van den Broek NM \& Curvers J. Reference intervals of reticulated platelets and other platelet parameters and their associations. Archives of Pathology and Laboratory Medicine 2013137 1635-1640. (https://doi.org/10.5858/arpa.2012-0624-OA)

16 Zhang GM, Xia YJ, Zhang GM, Zhu BL, Hu LY, Ma XB \& Zhou YT. Laboratory reference intervals of complete blood count for apparently healthy elderly people in Shuyang, China. Clinical Laboratory 201460 2081-2087. (https://doi.org/10.7754/clin. lab.2014.140320)

17 Karateke A, Kurt RK \& Baloglu A. Relation of platelet distribution width (PDW) and platelet crit (PCT) to preeclampsia. Ginekologia Polska 201586 372-375. (https://doi.org/10.17772/gp/2425)

18 Patrono C, Rocca B \& De Stefano V. Platelet activation and inhibition in polycythemia vera and essential thrombocythemia. Blood 2013 121 1701-1711. (https://doi.org/10.1182/blood-2012-10-429134)

19 Hoffmann JJ. Reticulated platelets: analytical aspects and clinical utility. Clinical Chemistry and Laboratory Medicine 201452 1107-1117. (https://doi.org/10.1515/cclm-2014-0165)

20 Honing ML, Morrison PJ, Banga JD, Stroes ES \& Rabelink TJ. Nitric oxide availability in diabetes mellitus. Diabetes/Metabolism Reviews 199814 241-249. (https://doi.org/10.1002/(sici)10990895(1998090)14:3<241::aid-dmr216>3.0.co;2-r)

21 Hotamisligil GS. Inflammation and metabolic disorders. Nature 2006 444 860-867. (https://doi.org/10.1038/nature05485)

22 Hagita S, Osaka M, Shimokado K \& Yoshida M. Adipose inflammation initiates recruitment of leukocytes to mouse femoral https://ec.bioscientifica.com https://doi.org/10.1530/EC-20-0209 (c) 2020 The authors Published by Bioscientifica Ltd

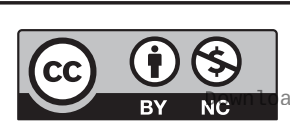

This work is licensed under a Creative Commons Attribution-NonCommercial 4.0 International License. ded from Bioscientifica.com at 04/26/2023 10:49:28AM 
artery: role of adipo-vascular axis in chronic inflammation. PLOS ONE 20116 e19871. (https://doi.org/10.1371/journal.pone.0019871)

23 Wannamethee SG, Lowe GD, Whincup PH, Rumley A, Walker M \& Lennon L. Physical activity and hemostatic and inflammatory variables in elderly men. Circulation 2002105 1785-1790. (https:// doi.org/10.1161/hc1502.107117)

24 Martin JF, Slater DN, Kishk YT \& Trowbridge EA. Platelet and megakaryocyte changes in cholesterol-induced experimental atherosclerosis. Arteriosclerosis 19855 604-612. (https://doi. org/10.1161/01.atv.5.6.604)

25 Barale C \& Russo I. Influence of cardiometabolic risk factors on platelet function. International Journal of Molecular Sciences 202021 623. (https://doi.org/10.3390/ijms21020623)

26 Vagdatli E, Gounari E, Lazaridou E, Katsibourlia E, Tsikopoulou F \& Labrianou I. Platelet distribution width: a simple, practical and specific marker of activation of coagulation. Hippokratia 201014 28-32.

27 Colafella KMM \& Denton KM. Sex-specific differences in hypertension and associated cardiovascular disease. Nature Reviews: Nephrology 201814 185-201. (https://doi.org/10.1038/ nrneph.2017.189)

28 De Luca G, Venegoni L, Iorio S, Secco GG, Cassetti E, Verdoia M, Schaffer A, Coppo L, Bellomo G, Marino P, et al. Platelet distribution width and the extent of coronary artery disease: results from a large prospective study. Platelets 201021 508-514. (https://doi.org/10.310 9/09537104.2010.494743)

29 Kotani K, Sakane N, Saiga K, Mu H \& Kurozawa Y. Clustered components of the metabolic syndrome and platelet counts in Japanese females. Clinical Chemistry and Laboratory Medicine $2007 \mathbf{4 5}$ 376-379. (https://doi.org/10.1515/CCLM.2007.063)
30 Park BJ, Shim JY, Lee HR, Jung DH, Lee JH \& Lee YJ. The relationship of platelet count, mean platelet volume with metabolic syndrome according to the criteria of the American Association of Clinical Endocrinologists: a focus on gender differences. Platelets 201223 45-50. (https://doi.org/10.3109/09537104.2011.589014)

31 Baatout S. Interleukin-6 and megakaryocytopoiesis: an update. Annals of Hematology 199673 157-162. (https://doi.org/10.1007/ s002770050220)

32 Pérez-Bautista O, Ramírez-Venegas A, Escobar-Arriaga E \& Sansores RH. Differences in inflammatory markers in a non-smoking and smoking Mexican population. Revista de Investigacion Clinica $200961205-211$.

33 Pamukcu B, Oflaz H, Onur I, Cimen A \& Nisanci Y. Effect of cigarette smoking on platelet aggregation. Clinical and Applied Thrombosis/Hemostasis 201117 E175-E180. (https://doi. org/10.1177/1076029610394440)

34 Zhang QH, Das K, Siddiqui S \& Myers AK. Effects of acute, moderate ethanol consumption on human platelet aggregation in platelet-rich plasma and whole blood. Alcoholism, Clinical and Experimental Research 200024 528-534. (https://doi. org/10.1111/j.1530-0277.2000.tb02021.x)

35 Larkin EC \& Watson-Williams EJ. Alcohol and the blood. Medical Clinics of North America 198468 105-120. (https://doi.org/10.1016/ S0025-7125(16)31244-5)

36 Kweon SS, Shin MH, Nam HS, Jeong SK, Park KS, Choi JS \& Lee YH. Sex differences in the associations of testosterone and sex hormonebinding globulin with metabolic syndrome in middle-aged and elderly Koreans: the Namwon study. Circulation Journal $2013 \mathbf{7 7}$ 734-740. (https://doi.org/10.1253/circj.cj-12-0613)

Received in final form 26 May 2020

Accepted 18 June 2020

Accepted Manuscript published online 19 June 2020
This work is licensed under a Creative Commons Attribution-NonCommercial 4.0 International License. ded from Bioscientifica.com at 04/26/2023 10:49:28AM 